\title{
ADAPTATIONS FOR URINARY MARKING IN RODENTS: PREPUCE LENGTH AND MORPHOLOGY
}

\author{
J. A. MARUNIAK, GLAUDE DESJARDINS AND F. H. BRONSON \\ Department of Zoology, The University of Texas, Austin, Texas 78712, U.S.A.
}

(Received 21st January 1975)

\begin{abstract}
Summary. Urine marking was examined in house mice, deermice, gerbils and hamsters. The frequency of urine deposition varied with the species, and a correlation is suggested between the propensity of males to mark in this fashion and prepuce length and morphology. We postulate an adaptational advantage for a long penis sheath and for a particular configuration of the prepuce; i.e. to act as a wick for the deposition of urinary pheromones.
\end{abstract}

The use of urinary and/or sebaceous gland pheromones to time many behavioural and physiological events in the reproductive processes of rodents is well documented (Bronson, 1971). Also well established is the occurrence in many species of specific behaviour patterns by which scent marking is accomplished with exocrine gland secretions (Johnson, 1973). Observations on behaviour and visualization of urine deposits under ultraviolet light have suggested that specific, reflexive motor patterns are involved in the deposition of this pheromone-rich substance, at least in male house mice (Desjardins et al., 1973; Maruniak et al., 1974). To assess the extent to which other rodents might similarly utilize marking with urine, three other species were investigated and compared with the mouse.

Laboratory stocks of four species of rodents were studied: the deermouse, Peromyscus maniculatus bairdii; the Mongolian gerbil, Meriones unguiculatus; the golden hamster, Mesocricetus auratus; and the wild house mouse, Mus musculus. With the exception of two groups of deermice, which will be described later, all individuals of each species were weaned at 21 to 28 days of age and isolated until they were tested as adults ( $>80$ days of age in all cases). Urinary marking patterns were observed following $2 \mathrm{hr}$ tests performed in bottomless $30 \times 30 \times 15$ $\mathrm{cm}$ cages divided by a wire-mesh $(0.2 \times 0.2 \mathrm{~cm})$ partition (Maruniak et al., 1974). The test enclosures were placed on $58 \times 68 \mathrm{~cm}$ sheets of Whatman No. 2 filter paper and examined after air drying under u.v. light $(15 \mathrm{~W}, 3666 \mathrm{~A})$. Males of each species were placed singly into one chamber of a test enclosure in one of three social situations: (a) alone, i.e. the other chamber was empty, or with (b) a male conspecific, or (c) a female conspecific in the other chamber. Animals were tested only once. Ten adult males of each species were anaesthetized and the lengths of the penis sheath, leg and body were measured. Other males from each species were killed and the entire prepuce was fixed in Zenkerformol and prepared for histological examination. 
During the tests under these conditions, male hamsters urinated only infrequently, male gerbils urinated at the rate of about once every 6 min, male deermice deposited urine about once every $1.7 \mathrm{~min}$, and male house mice deposited urine every 15 to $24 \mathrm{sec}$ (Table 1). Typical marking patterns for each species are shown in Pl. 1, Figs $1 \mathrm{~b}$ to $4 \mathrm{~b}$; male deermice and house mice deposited their urine on the cage floor in numerous small but discrete spots or streaks (Pl. 1, Figs 3b and $4 \mathrm{~b}$ ). Urine deposited by gerbils typically appeared in the form of a few large pools (Pl. 1, Fig. 2b). In contrast to the other species, little or no urine was deposited by male hamsters during the $2 \mathrm{hr}$ tests (Pl. 1, Fig. 1b), but other observations in our colony have established that males of this species typically release their urine in large quantities in the corners of their cages. The females used in these experiments were tested without regard to the stage of the oestrous cycle, and their marking was not subjected to detailed examination.

Table 1. Indices of relative length of the prepuce and mean number of urine marks deposited in 2-hr period among males of four species of rodents when tested under three social conditions

\begin{tabular}{|c|c|c|c|c|c|}
\hline \multirow{2}{*}{ Species } & \multicolumn{2}{|c|}{ Ratio of prepuce to: } & \multicolumn{3}{|c|}{ No. of marks (mean \pm S.E.) } \\
\hline & Body length & Leg length* & Isolated $\sigma^{*}$ & $\delta: 0 *$ & $8: q$ \\
\hline $\begin{array}{l}\text { Hamster } \\
\text { Gerbil } \\
\text { House mouse } \\
\text { Deermouse }\end{array}$ & $\begin{array}{l}1: 43 \\
1: 26 \\
1: 22 \\
1: 13\end{array}$ & $\begin{array}{l}1: 10 \\
1: 7 \\
1: 5 \\
1: 4\end{array}$ & $\begin{array}{c}3 \pm 1 \\
20 \pm 3 \\
303 \pm 64 \\
72 \pm 8\end{array}$ & $\begin{array}{c}3 \pm 1 \\
23 \pm 2 \\
393 \pm 23 \\
74 \pm 13\end{array}$ & $\begin{array}{r}5 \pm 1 \\
27 \pm 3 \\
473 \pm 91 \\
67 \pm 12\end{array}$ \\
\hline
\end{tabular}

The numbers of animals tested under each condition were 10 to 18 hamsters, 14 to 28 gerbils, 10 to 24 deermice, and 6 to 14 house mice.

* Measured from groin to ankle when anaesthetized.

A positive correlation was observed between the relative length of the prepuce and frequency of urination (see Table 1 and Plate 1), but the positions of the house mice and deermice appeared to be transposed. It was thought that the failure to observe a 'perfect' correlation might be traceable to the fact that deermice seldom engage in overt male-male aggression unless in the presence of females or after sexual experience (Bronson, 1967), and, hence, their urine marking under the present test conditions might not have been maximal. Two additional studies examined this possibility. In one, a group of ten male deermice, selected from the same stock and with identical backgrounds as those tested previously (and matched in age to the experimental males in Table 1 ), were paired with a receptive female for 1 week before testing. Animals of this group were then tested individually with a male in the other compartment

\section{EXPLANATION OF PLATE 1}

The external appearance of the prepuce (a), the typical pattern of urine marking demonstrated by u.v. light, in the 2-hr test (b), and cross-sections of the distal regions of the prepuce (c) of the hamster (Fig. 1), the Mongolian gerbil (Fig. 2), the house mouse (Fig. 3), and the deermouse (Fig. 4). Note the length of the preputial sheath relative to the ankle. Fig. 1c, $\times 11$; Fig. 2c, $\times 10$; Fig. 3c, $\times 14$; Fig. 4c, $\times 15$. 
Pl. IT' I
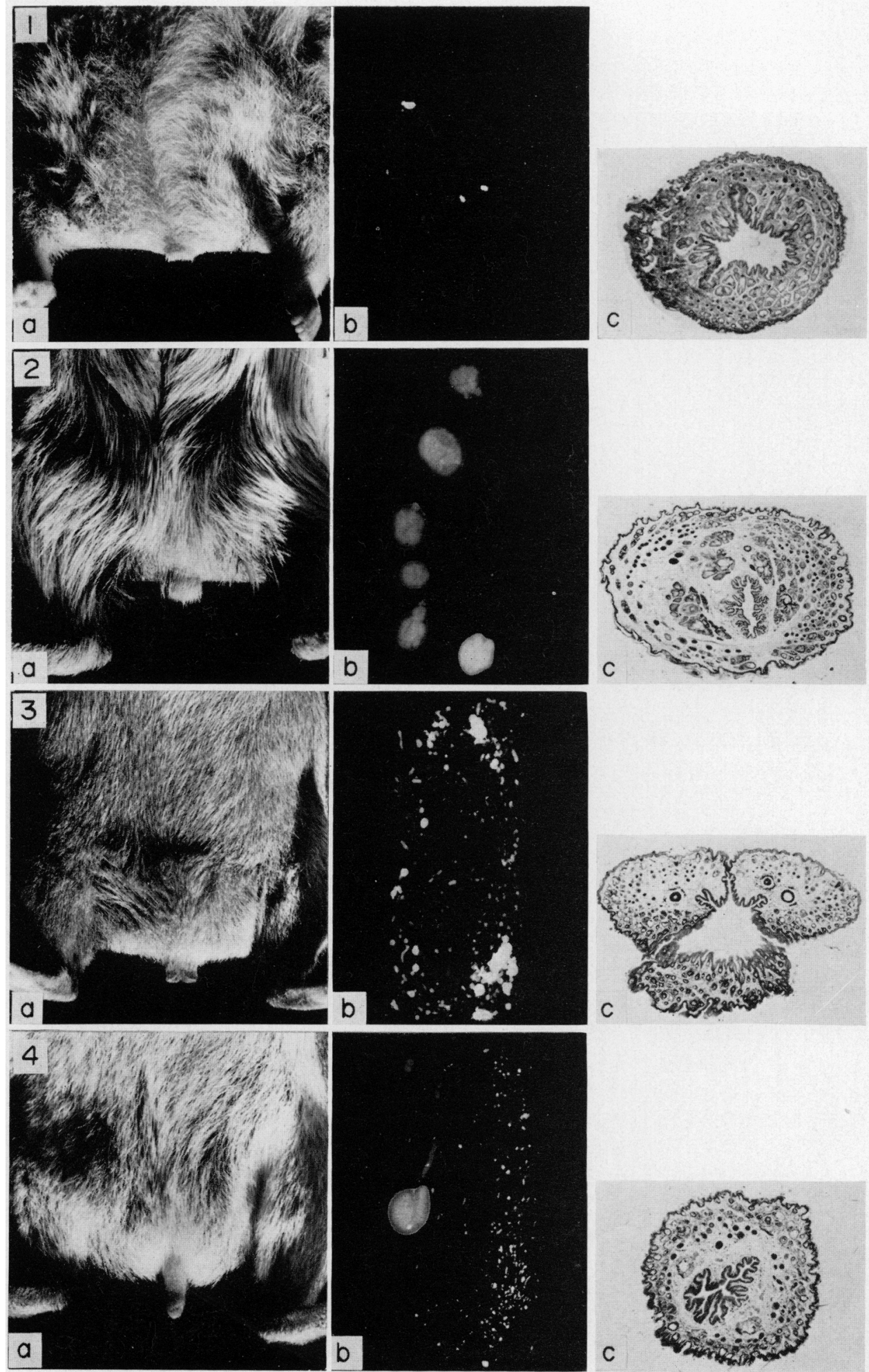

(Facing p. $568:$ 


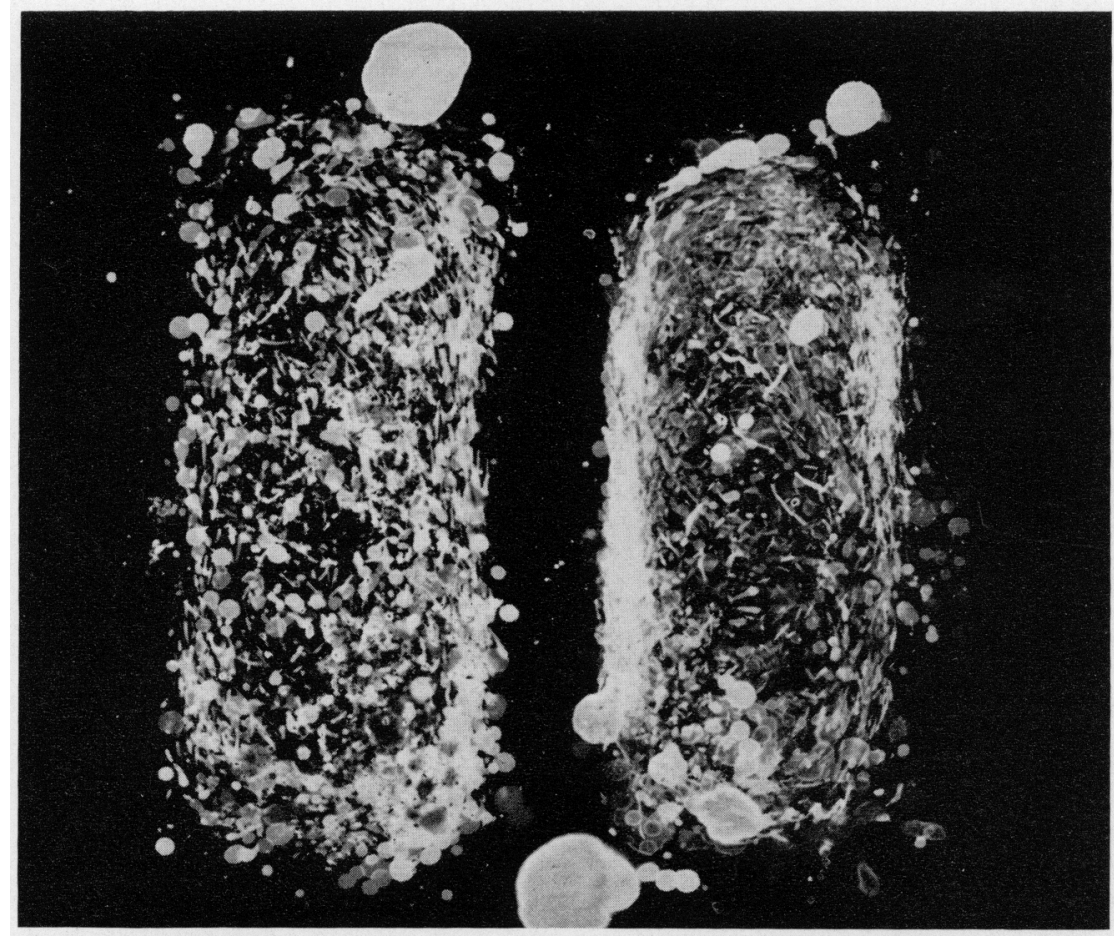

fiki, J. Urinary marking patterns during an overnight test of two colony stud decrmice. 
of the test enclosure; an average of $2 \cdot 2$-fold more marks were produced than by the sexually inexperienced males tested previously (159 \pm 37 marks $/ 2 \mathrm{hr}$; $P<0.01$ when compared to the other groups of deermice shown in Table 1). A second group of sexually experienced colony stud males, all $>1$ year of age, were tested overnight, one in each half of the test enclosure. These males marked at variable rates, and some marked too frequently for accurate counting as shown in Pl. 2, Fig. 5. Thus, the marking responses of male deermice appear to be variable under our testing procedures, but at least some males mark with urine at extremely high rates and at least some of the observed variation is traceable to the presence or absence of sexual experience. Hamsters and gerbils, therefore, which are known to use exocrine glands for scent marking and are not known to possess urinary pheromones (Thiessen et al., 1971; Johnson, 1973), have relatively short prepuces and deposit their urine only infrequently and characteristically in large pools. Deermice and house mice possess priming and signalling urinary pheromones, have relatively long prepuces, and distribute their urine in the form of many small discrete marks. That such urine deposition is true scent marking has been verified for male house mice for which either social or substrate novelty is the prime factor eliciting such behaviour (Maruniak et al., 1974). In the present experiments, involving animals isolated for long periods, all test situations were more or less equal in novelty and the failure to detect greater differences in the marking responses of house mice to the various stimulus situations was expected.

Histological comparisons of the outermost regions of the prepuce suggest an additional set of apparent adaptations in the house mouse. The distal extremities of the prepuce appear bifurcated (Pl. 1, Fig. 3c), with each bifurcation containing a terminus of a preputial gland duct. The preputial glands produce lipids known to have sex attractant qualities in males of this species (Bronson \& Caroom, 1971). Additionally, the tip of the house mouse prepuce possesses many long hairs which may act as brushes during urinary marking. Finally, the distal regions of the lumen of the house mouse prepuce are convoluted to a much greater extent than in the other species examined (Pl. 1, Figs $1 \mathrm{c}, 2 \mathrm{c}$ and $3 \mathrm{c}$ ), and the tip of the penis lies well within the interior of the sheath, providing a reservoir for urine accumulation. By contrast, the lumen of the hamster's prepuce has few convolutions, and the tip of the penis lies in close proximity to the luminal terminus. The prepuce of the gerbil and of the deermouse seems intermediate, but, like the house mouse, the tip of the deermouse penis appears to reside well inside the sheath.

On the basis of the above descriptions and comparisons, we postulate that a potential morphological adaptation of the penis sheath in rodents is one enabling it to act as a wick for the deposition of urine and, hence, urinary pheromones. It is possible that a long preputial sheath, relative to height above the ground, would be an energy-conserving adaptation allowing frequent deposition of urine while engaging in normal home-range or territorial activities, and the requirement for specific muscular involvement during such marking would be less. Observations of house mice placed on a sheet of plexiglass showed that the movements associated with this response are indeed so subtle that it was difficult to determine when marking occurred. Females would thus 
be expected to mark infrequently, and, typically, this is what has been found (Maruniak et al., 1975). Specific adaptational correlates in addition to a long penis sheath might also be expected; the luminal reservoir and wick-like characteristics described for the house mouse prepuce could be considered as such.

This work was supported by U.S. Public Health Grants HD-03803 and HD-07381 from the National Institute of Child Health and Human Development. We thank Doug Baxter for technical assistance.

\section{REFERENCES}

BRONsON, F.H. (1967) Effects of social stimulation on adrenal and reproductive physiology of rodents. In Husbandry of Laboratory Animals, pp. 513-542. Ed. M. Conalty. Academic Press, New York.

Bronson, F.H. (1971) Rodent pheromones. Biol. Reprod. 4, 344-357.

BRonson, F.H. \& Garoom, D. (1971) Preputial gland of the male mouse: attractant function. F. Reprod. Fert. 25, 279-282.

Desjardins, C., Maruniak, J.A. \& Bronson, F.H. (1973) Social rank in house mice: differentiation by ultra-violet visualization of urinary marking patterns. Science, N.Y. 182, 939-941.

Johnson, R.P. (1973) Scent marking in mammals. Anim. Behav. 21, 521-535.

MARuniak, J.A., Owen, K., Bronson, F.H. \& DesJardins, G. (1974) Urinary marking in male house mice: responses to novel environmental and social stimuli. Physiol. Behav. 12, 1035-1039.

Maruniak, J.A., Owen, K., Bronson, F.H. \& Desjardins, C. (1975) Urinary marking in female house mice: effects of ovarian steroids, sex experience, and type of stimulus. Behav. Biol. 13, 211-217.

Thiessen, D.D., OWEN, K. \& Lindzey, G. (1971) Mechanisms of territorial marking in the male and female Mongolian gerbil (Meriones unguiculatus). 7. comp. Physiol. Psychol. 77, 38-47. 